\title{
Environmental risk assessment of intensive beekeeping integrated with aquaponic system
}

\author{
Constanta Laura Augustin (Zugravu), Cristian Muntenita, Ciprian Petrisor Plenovici, \\ Gheorghe Adrian Zugravu \\ "Dunărea de Jos" University of Galaţi, Galati, Romania
}

\begin{abstract}
The paper main objectives are to identify an analysis model for development of integrated aquaponics with intensive beekeeping. The socio-economic environmental impact assessment provides the opportunity to analyze the determinants of public attitude towards the use of multifunctional aquapson. In relation to the other agricultural production branches, beekeeping integrated into aquaponic systems is an environmentally friendly technology that does not use additional energy supply within the integrated production system and also recycles waste water from aquaculture through mechanical, biological filters and plant roots.
\end{abstract}

Key words: intensive beekeeping, aquaponiq; risk analysis;

\section{Introduction}

Honey consumption at European level is about 20-25\% of world consumption, being 0.70 kilograms per person per year. So the EU is one of the largest importers in the field, with annual honey imports ranging between 120 000 and 150000 tonnes. The main suppliers are China, with 63900 tonnes (43\% of total EU imports), Argentina with 22300 tonnes, Mexico with 21200 tonnes, and Ukraine with 8900 tonnes of honey [1]. Also, the low price of bee products in China leads to lower exports from EU member states. Support for European apiculture In recent years, the EU has implemented support programs and policies for beekeepers. These measures have taken into account the problems faced by European beekeepers, namely the massive loss of bee colonies, honey production costs and fierce competition in the market. The progress of beekeeping will contribute to increasing the competitiveness of this sector and the economic development of rural areas, and by pollination, bee colonies will continue to act as providers of important environmental services, ensuring the sustainable development of these areas.

Aquaponics systems have become increasingly popular todaycan be integrate with intensive beekeeping as a modern industrial farming model. It is a relatively new idea to integrate intensive beekeeping with aquaponics, to use of same water in order to growth fish, bees and plants in a single system.

\section{Risk analysis}

The Mathematical model of the evolution water quality parameters and the accepted mathematical structures can help establish a more comprehensive map of risk factors.

Based on this definition, the phrase "everyone manages risk" is therefore true. If we accept that all individuals and organizations have goals, that these goals are necessarily set in the future and that the future is uncertain, then each and every organization manages the risk.

The risk management system provides tools to build a structured vision of the future and to address the issue of related uncertainty. Implementing risk management in an organization or regulatory body gives management the opportunity to make rational decisions based on available information, no matter how full it is. In order to prove the feasibility of implementing a risk management system, we will return to the fundamental principle of project management, which characterizes the interdependence of the following parameters: the budget, the quality of the finished product and the implementation time. Risk management tools help to make a rational choice among a number of alternatives. In other words, the level of achievement of the desired regulatory objective will depend on the cost of the preventive measures and the abandonment of the

Corresponding Author: Gheorghe Adrian Zugravu, "Dunărea de Jos” University of Galaţi,Galati, Romania, zugravuadrian@yahoo.com 
expected benefits from one or more areas of economic activity.

There are several sources of risk. To identify the risk, the project team should review the scope of the program, cost estimates, program (including critical path evaluation), technical maturity, key performance parameters, performance challenges, stakeholders' expectations of the current plan, external dependencies, and internal challenges, integration, interoperability, sustainability, supply chain vulnerabilities, threat management, cost deviations, test event expectations, safety, security, and more.

The analysis of the factors influencing entrepreneurship risk in the beekeeping sector was made using the research method as research method, and the research tool chosen is the questionnaire. The reason for choosing this method is the desire to get the most relevant information about the factors of influence of entrepreneurship risk in the beekeeping sector in the North-West Region and the extent to which beekeepers have succeeded or intend to access European funds. The questionnaire is designed to get as much data as possible on the factors that influence a beekeeper's decision to start a beekeeping business, the level of knowledge and education, the determination of the degree of access to European funds, the collaboration with companies in beekeeping sector, etc. After the investigation, a centralization of the questionnaires was carried out, followed by data interpretation and analysis.

\section{Results and discussions}

Since 2000, the number of bee families has been progressively increasing due to the financial support provided by the government through the measures meant to support rural development in a first stage, and then due to the European funds allocated after Romania's accession to the European Union. For the development of the beekeeping sector in Romania, it is necessary to consider the intensification and diversification of production, increase of bee family, quality assurance of production.

Besides the melliferous characteristics, Lophantus Anisatus is also a medicinal herb, considering its therapeutic and calming properties. The aroma of the plant is a woven one, between anise and fennel, a flavor that gives it uniqueness and distinction. Temperature controls the rate of plant growth.

The flower of Lophantus Anisatus blooms for a long period of time, about 5-6 months, from June until the coming of frost that is October to November. In the second year of development it blooms even 10-15 days earlier.
Bees do not usually fly when the temperature is below $10{ }^{\circ} \mathrm{C}$. Some flight will occur at $12-14{ }^{\circ} \mathrm{C}$ if the day is still and sunny. Good flight begins at $16^{\circ} \mathrm{C}$, and at 19 ${ }^{\circ} \mathrm{C}$, it reaches a relatively high level. In poor weather, bees may only fly about 150 metres from the hive between showers. Flight is reduced a little on very overcast days, especially if it is cool. Strong winds make it difficult for bees to fly and the number of foraging trips per day may be reduced.

Where the distance between the hives and target crop is greater than 150 metres, bees will be unlikely to visit the blossom in inclement weather, because foraging in these conditions is limited to short trips. In contrast, hives in almond plantations where temperatures are warmer are placed in large groups around the edge, and in the centre of blocks of trees.

Beekeepers must provide and maintain a supply of clean water of suitable mineral content for the bees in each place where bees are kept. The water should not be more than 200 metres from any hive. Beekeepers in other states and territories should check the relevant legislation and beekeeping or apiary code of practice. Where possible, locate hives in a sunny north to northeast facing site, sheltered from cold southerly and westerly winds. Bees are less inclined to forage when hives are located in cool, shaded areas. Keep hive entrances clear of weeds. In summer, provide partial shade. Ensure the bees have access to clean, fresh water. Place hives in positions where they are not affected by flood or spray irrigation. Bees are generally not inclined to fly into crops covered by hail netting, especially if the netting causes significant shading. It is best to place hives in the crop under the netting. Bees will usually prefer flowers with the highest concentration of sugar, for example, apples (approximately 23\% nectar sugar) in preference to pear (approximately $7 \%$ nectar sugar). Honey bees are very good pollinators of many flowering plant species. The hairy nature of bees enables them to carry large numbers of pollen grains during foraging. As they brush against the reproductive parts of flowers, pollen grains are picked up and deposited. The fusion of pollen with an ovule is known as fertilisation and this causes development of seed or fruit. Although bees may do an excellent job in transferring pollen, factors affecting fertilisation can cause poor fruit and seed set. Many horticultural and seed crops require bee pollination to ensure good, economic yields. Some fruits such as almonds, apples, cherries, pears and plums, require compatible pollen of another variety or cultivar of the same species. This is known as cross-variety pollination. Where cross-variety pollination is required in an orchard, a main crop variety and a polliniser variety are planted. Interchange of pollen between the two varieties occurs when a bee visits both varieties on 
the one foraging trip. Some interchange of viable pollen grains can also occur when forager bees brush against each other in the hive. Pumpkins, zucchinis, cucumbers, melons and kiwi-fruit, have separate male and female flowers and pollen must be transferred to female flowers. The flowers of some plants such as berries, pumpkins and kiwifruit, have more than one stigma and more than one ovule. They need multiple visits by bees to ensure sufficient pollen grains are placed on the receptive stigmas to produce well-formed fruit. In addition to yield, pollination can improve quality in some crops. For example, high seed numbers improve the size of apples and pears, as well as their storage qualities. Low seed numbers and uneven seed distribution in the ovary can cause small and/or misshapen fruit. Bee colonies must be prepared well in advance of flowering so that they conform to certain standards to give growers the best pollination result. The beekeeper and grower should agree on a pesticide spray program to avoid damage to the bees. The use of a written contract will provide both parties with an understanding of their responsibilities.

The number of colonies (hives) required per hectare of crop for pollination is known as the stocking rate and will vary according to a number of factors. High stocking rates are used for densely planted crops where there are more flowers. Older fruit trees will require more bees than younger trees because they also have more flowers. Large numbers of colonies are sometimes recommended for crops that are relatively unattractive to bees as this allows for the loss of those foragers that desert the crop to seek more attractive flora elsewhere. In addition to bees managed by beekeepers, wild (feral) bee colonies can also help to pollinate crops. Their contribution to pollination will depend on the number of colonies in the surrounding area, as well as the number of foragers in the colony. Because wild bees are subject to bee disease and pests, as well as nectar and pollen shortages, the number of bees in these colonies may be quite low compared to that of a managed colony. In adverse field conditions, wild colonies may die or become seriously weakened with few foragers left to deliver a good pollination result for growers.

There should be ample comb space for the queen to lay eggs so that there is always a large amount of unsealed larvae, preferably about $25 \%$ of the total amount of brood. The presence of larvae creates a demand for pollen, and pollen foragers are usually the most efficient pollinators. When other nectar and pollen yielding flora, such as weeds, are available, colonies can quickly expand and become too populous. If this occurs they should be weakened or divided to prevent swarming. Preparation of colonies for early spring pollination should begin in autumn, taking advantage of autumn nectar and pollen flows. The colonies will then overwinter with large numbers of bees. They may be wintered in double or single box hives, with sufficient stores to carry them through winter and the early pollination period. Some supplementary feeding may be necessary in late winter to stimulate brood rearing and increase the number of adult bees. Feeding may also be necessary when honey stores are low during the pollination period, or immediately after it. In general, for crops that flower after mid-spring, preparation of colonies should begin four to six weeks in advance so that there is a good population of bees ready to forage as soon as hives are introduced to the crop. Brood rearing can be encouraged by placing the hives on good buildup flora prior to the period of pollination [16].

Aquaponic it is a food production system which combine hydroponic vegetables production and aquaculture into a closed recycled system. This combination of production methods of integrated multitrophic hydroponic and aquaculture remove problems associated with methods of output individual [3], [5], [10].

Main problem of recirculating systems in aquaculture it is production of waste rich nitrates, the water which must treat and which provoke environment problem [2], [4], [11].

For hydroponic systems, main problem it is addiction of chemical fertilizers.

The main benefits of beekeeping integrated with aquaponic systems:

- The three types of products can be obtained into the same system (fish, mint and honey).

- Production of mint it is obtained without generate a competition for nutrients and it is integrated with intensive beekeeping system [13], [15].

- Green aquaculture it is, management technique that help to support business of aquaculture to take measures for environment natural resources protection. Through this theme of research, I propose:

- improving management of waste and of reduction quantities of waste eliminated improper, recovery efficiency and intelligence of resources [6], [7], [12].

- $\quad$ integration beekeeping with acvaponia represent a model of sustainable business, ecological based on economic viability and competitiveness, represent a scientific upcoming concern.

- integration the system of aquaculture with production of asian mint and also with intensive beekeeping; 
- $\quad$ adoption a business model of integrated fish, beekeeping and aromatic obtained from species of Lophantus Anisatus mint grow into the acvaponic system [8], [9], [14];

- to integrate social activities which follow reaching social, economic and of environment objectives through actions of processing, marketing and which add value to finished products;

- $\quad$ The technical implementation of the right type of hydroponic system will determine the success or failure of entire operation. With that in mind, the aquaponic system design phase is the first step towards a proper implementation process.

Socio economical impact evaluation supplies understanding around the determinants of public attitudes towards multi-use aquaponic.

\section{Conclusions}

Intensive beekeeping integrated in aquaponic systems represent a modern production system wich can incrise the rol of wild bee species in crops pollination. The environmental risk for an integrated model in both intensive beekeeping and aquaponics determine the economic condition and the causes that have influenced the results obtained.

\section{References}

[1] Abrol DP (2012). Pollination Biology: Biodiversity Conservation and Agricultural Production. Springer Dordrecht Heidelberg London New York. ISBN 978-94-007-1941-5.

[2] Addy, M.M., Kabir, F., Zhang, R., Lu, Q., Deng, X., Current, D., Griffith, R., Ma, Y., Zhou, W., Chen, P., Ruan, R., 2017. Co-cultivation of microalgae in aquaponic systems. Bioresource Technology, 245: 27-34.

[3] Adler, P.R., J.K. Harper, E.W. Wade, F. Takeda and S.T. Summerfelt, 2000. Economic analysis of an aquaponic system for the integrated production of rainbow trout and plants. International Journal of Recirculating Aquaculture. 1(1): 15-34.

[4] Bhatnagar A and P Devi, 2013. Water quality guidelines for the management of pond fish culture. International Journal of Environmental Science, 3: 6 .

[5] Bosma, R.H., Lacambra, L., Landstra, Y., Perini, C., Poulie, J., Schwaner, M.J., Yin, Y., 2017. The financial feasibility of producing fish and vegetables through aquaponics. Aquacultural Engineering, 78:146-154.
[6] Francis-Floyd R, C Watson, D Petty and DB Pouder, 2009. Ammonia in aquatic systems (Univ. Florida, Dept. Fisheries Aquatic Sci., Florida Coop. Ext. Serv. FA-16), $<$ http://edis.ifas.ufl.edu/FA031>. Date of Access 01 January, 2015.

[7] Graber, A., Junge, R., 2009. Aquaponic Systems: Nutrient recycling from fish wastewater by vegetable production. Desalination, Volume 246, Issue 1:147-156.

[8] Johnston P, Huxdorff C, Simon G \& Santillo D (2014). The Bees' Burden. An analysis of pesticide residues in comb pollen (beebread) and trapped pollen from honey bees (Apis mellifera) in 12 European countries. Eds $\mathrm{S}$ Erwood. Greenpeace Research Laboratories Technical Report 03-2014. http://www.greenpeace.to

[9] Klein AM, Vaissiére BE, Cane JH, SteffanDewenter I, Cunningham SA, Kremen C, Tscharntke T (2007). Importance of pollinators in changing landscapes for world crops. Proceedings of the Royal Society B: Biological Sciences. 274: 303-313.

[10] Kotzen B. and S. Appelbaum. 2010. An investigation of aquaponics using brackish water resources in the Negev Desert. Journal of Applied Aquaculture 22: 297-320.

[11] Lal R, 2013. Beyond Intensification. In: Paper presentation at the ASA, CSSA, \& SSSA international annual meetings, Tampa, Florida, USA.

[12] Liang, J.Y., Chien, Y.H., 2013. Effects of feeding frequency and photoperiod on water quality and crop production in a tilapia-water spinach raft aquaponics system. International Biodeterioration and Biodegradation, Volume 85: 693-700.

[13] Michener CD (2007). The bees of the world. 2nd edition, Baltimore, The John Hopkins University Press. (Cited in Pfiffner \& Müller 2014).

[14] Radosavljević V., M. Ćirković, D. Ljubojević, D. Jakić-Dimić, Z. Marković, J. Žutić, and V. Milićević. 2014. Searching for solutions in aquaculture: aquaponics. Arhiv veterinarske medicine 7: $71-78$.

[15] Ragnheidur Thorarinsdottir, 2015, Report on design and risk analysis D2.3 Ecoponics - Cofunded by the Eco-Innovation Initiative of the European Unuion;

[16] Tirado R, Simon G \& Johnston P (2013). Bees in decline: A review of factors that put pollinators and agriculture in Europe at risk. Greenpeace Research Laboratories Technical Report (Review) 01-2013, publ. Greenpeace International: $48 \mathrm{pp}$. 